\title{
CAD IN WOMEN
}

\author{
Maddury Jyotsna
}

As there is global increase with epidemic of coronary artery disease (CAD) in Asia, multiple studies are concentrated in this field. The gender differences in CAD presentation, evaluation and management were dilated for more than a decade in the literature.

We have two important papers on the issue of "CAD in Women". Previous studies showed that in hospital outcome following the percutaneous intervention (PCI) for females and males were similar with difference at one year major adverse cardiovascular events (MACE). But in 2016 Joshua Schulman-Marcus et from CONFIRM registry[1] data demonstrated that to difference in mortality between the diabetic males and females. Similar results are produced by Raghu kishor Galla et al in their study “Outcomes Of Coronary Angioplasty In Diabetic Patients - A Retrospective Study" published in this issue. Probably the known factors for the gender difference for PCI and immediate post PCI management like bleeding and weight adjusted all drug dosage[2], along with the persistent progressive improvement in PCI technology $[3,4]$ made the difference of outcome to disappear at one year.

Now we have to take steps to progress and prevention of CAD in the Asian population [5,6]. Best step to start with the risk factor(RF) control after knowing the burden of RF, which is heighted in the article of this issue on "Gender Difference In Risk Factor Profiles In Patients Referred For Coronary Angiogram" by Deepti el al. According to this study the incidence of risk factors are more in females either they have the CAD or not. With the restriction of referral bias of study population which were only patients undergoing coronary angiogram (CAG), this may reflect the general higher incidence in general population.

We require several studies like this in "CAD in women" to improve the disease status in our continent.

\section{REFERENCES:}

1. Joshua Schulman-Marcus, MD; Bríain ó Hartaigh, PhD; Heidi Gransar, MS; Fay Lin, MDa; Valentina Valenti, MD; Iksung Cho, MD; Daniel Berman, MD; Tracy Callister, MD, Augustin DeLago, MD; Martin Hadamitzky, MD; Joerg Hausleiter, MD; Mouaz AlMallah, MD; Matthew Budoff, MD, Philipp Kaufmann, MDh; Stephan Achenbach, MDi; Gilbert Raff, MDj; Kavitha Chinnaiyan, MDj. Sex-Specific Associations Between Coronary Artery Plaque Extent and Risk of Major Adverse Cardiovascular Events: The CONFIRM Long-Term Registry , J Am Coll Cardiol Img. 2016;9(4):364-372.

2. Fareed J1, Hoppensteadt DA, Bick RL. Management of thrombotic and cardiovascular disorders in the new millenium. Clin Appl Thromb Hemost. 2003 Apr;9(2):101-8. 
3. Reddy K, Khaliq A, Henning RJ. Recent advances in the diagnosis and treatment of acute myocardial infarction. World J Cardiol. 2015 May 26;7(5):243-76.

4. Naito R, Miyauchi K, Konishi H, Tsuboi S, Ogita M, Dohi T, Kasai T, Tamura H, Okazaki S, Isoda K, Daida H. Temporal Trends in Clinical Outcome After Percutaneous Coronary Intervention 1984-2010 - Report From the Juntendo PCI Registry. Circ J. 2016;80(1):93-100. doi: 10

5. Najafipour H, Banivaheb G, Sabahi A, Naderi N, Nasirian M, Mirzazadeh A. Prevalence of anxiety and depression symptoms and their relationship with other coronary artery disease risk factors: A population-based study on 5900 residents in Southeast Iran. Asian J Psychiatr. 2016 Apr;20:55-60.

6. Bhatti GK, Bhadada SK, Vijayvergiya R, Mastana SS, Bhatti JS. Metabolic syndrome and risk of major coronary events among the urban diabetic patients: North Indian Diabetes and Cardiovascular Disease Study-NIDCVD-2. J Diabetes Complications. 2016 Jan-Feb;30(1):72-8. 